\title{
Exploration of Border Security Systems of the ROK Army Using ABMS and GA Algorithm
}

\author{
Kyungtack $\mathrm{Oh}^{1 \dagger} \cdot$ Jae-Yeong $\mathrm{Lee}^{2}$
}

\section{ABMS와 유전학적 알고리즘을 이용한 한국군 경계시스템에 관한 연구}

\author{
오경택·이재영
}

\begin{abstract}
This paper explores a border security system based on agent-based modeling and simulation (ABMS). The ABMS software platform, map aware non-uniform automata, is used to model various scenarios and evaluate the border security system given a set of infiltrators who have evolutionary behavior governed by genetic algorithm (GA). we formulated an optimization model and approximately solved it using a GA in order to capture near optimal behavior of an infiltrating force. The results presented give two significant insights for our border security system in that optimizing the infiltrator's behavior can make a significant difference and the quantitative results regarding the infiltrator's avoidance of each asset can be viewed as capturing their relative importance.
\end{abstract}

Key words : ABMS, Genetic Algorithm(GA), border security system

\section{요약}

본 논문은 에이전트 기반 모델링 및 시뮬레이션을 바탕으로 한 한국군 GOP 경계시스템에 관한 연구이다. 에이전트 기반 모델링 및 시뮬레이션 기반 소프트웨어인 MANA를 이용하여 다양한 시나리오를 모델링하고 유전학적 알고리즘을 통해 침투 양상이 변화하는 적에 대해 분석하였다. 우리는 유전학적 알고리즘을 이용하여 침투하는 적의 최적화된 행동에 근사하는 값을 구하기 위해 최적화 모델을 구성하였다. 그 결과는 GOP 경계시스템에서 침투하는 적의 행동에 대한 최적화가 경계시스템의 효과성에 현저한 차이를 가져온다는 점과 침투하는 적의 아군 자산에 대한 회피 정도는 각각의 자산의 중요성을 반영한다는 점에서 두 가지 중요한 통찰력을 제공한다.

주요어 : 에이전트 기반 모델링 \& 시뮬레이션, 유전학적 알고리즘, GOP 경계 시스템

\section{1. 서 론}

Border security systems are currently receiving significant attention internationally because of illegal immigrants, drug smuggling and armed conflict. In the U.S., most border security studies aim to optimize the detection rate with diverse assets for preventing such illegal

접수일(2012년 12월 12일), 심사일(2013년 6월 23일), 게재 확정일(2013년 6월 23일)

1) 육군사관학교 운영분석학과

2) 국방대학교 운영분석학과

주 저 자:오경택

교신저자 : 오경택

E-mail; kt6461@gmail.com activities on the border between the U.S. and Mexico and between the U.S. and Canada.

Some countries have serious potential for direct armed conflict, which can expand from small-sized engagements to regular war, as exemplified by South and North Korea, Israel and its neighbors and the Kashmir province between India and Pakistan. This study focuses on the border between South and North Korea, the so-called the Demilitarized Zone(DMZ).

In this study, part of the border security system in the DMZ is modeled in MANA (Map Aware Non-uniform Automata $)^{[1]}$ software for agent-based modeling, to explore the effects of the current security systems. Past 
research for the DMZ border security system has calculated detection rates of the enemy using human resources and Thermal Observation Devices (TODs) via probabilistic methods and heuristic algorithms ${ }^{[2]}$. This previous study gives theoretical results with limited surveillance resources but it also has several limitations which cannot represent real DMZ circumstances.

This study develops and analyzes a model of the ROK Army's border security system, which aims to prevent infiltration of the enemy in the DMZ. The analysis uses a $10 \times 7 \mathrm{~km}$ section of the DMZ, representing the area of responsibility of a battalion in the 5th infantry division.

The model is run multiple times, varying a large number of design points, i.e., values for the controllable and uncontrollable factors to provide insights to the following questions:

- what is the near optimal behavior of the infiltrator given the maximum border security system?

- Given the limited resources, what are the optimal combinations of sensors, surveillance and command and control(C2) systems to detect, classify and prevent enemy infiltrations into the DMZ?

\section{Model development}

\subsection{Why Use Agent-Based Modeling and Simulation}

For the study of the GOP border security system we employ the concept of ABMS which is characterized by the agents. In our model, the surveillance assets and infiltrators in the condition of DMZ are agents. The effectiveness of ABMS is outstanding as revealed in the result of Reonolds' artificial birds, Boids ${ }^{[3]}$ and there already exist several ABMS tools such as NetLogo, StarLogo, AnyLogic etc.

Some studies of center for Naval analysis, seed center $^{[4]}$ and pioneer works of Illachinski ${ }^{[5]}$ demonstrate the possibility of ABMS to overcome the limitations of the conventional mathematical model, Lanchester Equations ${ }^{[6]}$. The main properties of ABMS contribute to gain great insight to solve the GOP border security system as below $^{[5]}$ :

- Nonlinear interaction: The contact between infiltrators and security assets occurs based on the nonlinear interaction induced by the surveillance assets, decision making process through the hierarchical system;

- Network of agents: Network system between human resources and surveillance equipment helps sharing information and triggers the behavior of other agents;

- Emergent behavior: Certain events such as detection and direct / indirect contact of the enemy trigger the behavior of both friendly forces and infiltrators during the designated time length;

- Hierarchical structure: The border security system organized from the platoon to the battalion with C2 hierarchy;

- Adaptation: Both infiltrators and the border security assets are continuously sense the environment and change their behavior.

In addition to these five properties which well-explain the reality of the GOP border security system, nonequilibrium order, decentralized control, and non-reductionist are main features of the ABMS. Especially, five properties of ABMS differentiate this study from the previous work ${ }^{[2]}$ for the GOP border security system.

\subsection{GOP border security system model with MANA}

Based on the data and information how the security system implemented in reality, we develop the GOP border security system model by using MANA. Our focus on the GOP border security system model is not to describe details but to formulate the model which can be flexibly develop the scenarios and find surprise results from different scenarios based on the model. All of the data used in this model are based on the night operation in the DMZ.

The overall shape of the Korean DMZ is depicted in Fig. 1. The length of the DMZ is approximately $248 \mathrm{~km}(155$ miles $)$ and its maximum width is $4 \mathrm{~km}$. For this study, we selected an area in the middle of the DMZ. 
As Fig. 2 depicts, GOP lines are formed on each side of the DMZ from the center line, the military demarcation line(MDL). A guard post(GP) depicted in the Fig. 2 is a type of security element which is located between the MDL and GOP lines. We do not consider GPs in our study due to their sensitive and classified nature.

Fig. 3 shows the simple scenario of the border security

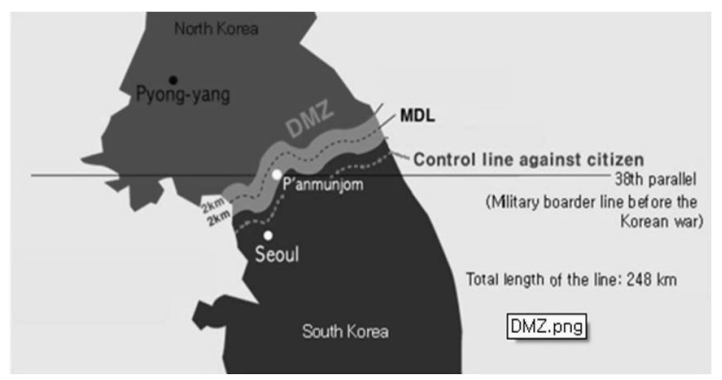

Fig. 1. DMZ between South and North Korea

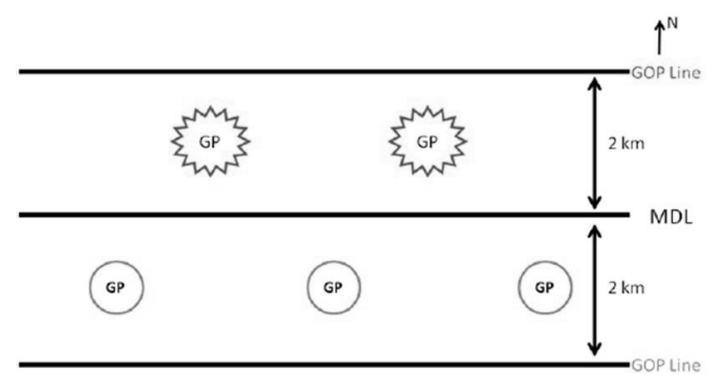

Fig. 2. Configuration of the $\mathrm{DMZ}$

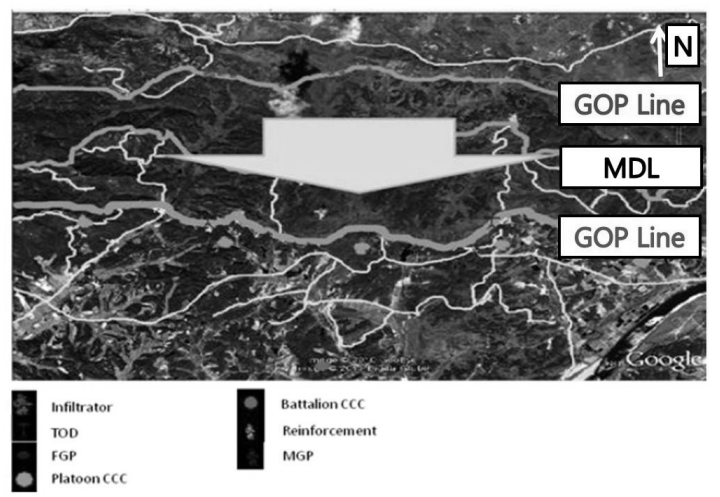

Fig. 3. Screenshot of the GOP border security system model model when the number of $\mathrm{FGP}=3, \mathrm{MGP}=3$ and Reinforcement $=8$ per platoon and the number of TOD $=2$ per battalion with terrain map. In this simple scenario, the TOD detects the infiltrator, sends the information to the battalion $\mathrm{CCC}$, then the battalion CCC makes decision and directs the platoon CCC to dispatch the reinforcement along with the GOP line. In our model, artillery assets, mines, and GP in the DMZ area does not considered but it can be described if necessary.

As MANA 4 has own unit, we define that the MANA distance unit $1=10 \mathrm{~m}$ and time unit $1=5 \mathrm{sec}$ and transform input parameters throughout the model.

\subsubsection{Infiltrator}

The behavior of the infiltrator is a significant variable which affects to the results such as probability the enemy is detected or killed, the probability the infiltrator's mission fails, and the (conditional) expected length of time for the enemy to reach their waypoint.

We only assume that the enemy has a longer detection range than the FGP and MGP when these defensive human resources are in their default state. Also, the objective of the infiltrators is to reach the waypoint without being killed. We exclude the case when the infiltrators attack the border security. State of the enemy defined as below:

- Infiltrator / default: This is the state before the infiltrator detects the border security and the behavior is defined as the ROK Army describes in the FM $32-1^{[8]}$.

- Infiltrator / contact: When the infiltrator detects the enemy, it triggers what we call the contact state and the infiltrator changes behavior. In this state, we modify specific model parameters including avoidance of certain assets and movement speed, which affects the results of the scenario.

\subsubsection{Human Resources}

There are three types of human resources in our model, the FGP, MGP and reinforcement as explained earlier. In our scenario, each platoon takes charge of 
$2 \mathrm{~km}$ width of the security area. We assume that the distance between FGPs is identical regardless of terrain and they are located along with the GOP line. We exclude the rotation of the FGPs and only consider MGP to make up the gaps between FGPs. Reinforcements are stationed in the platoon's CCC and dispatch to the GOP line when the platoon's CCC learns information from other assets such as FGP, MGP or the battalion's CCC. States of the human resources are defined as below:

- FGP/default: Sentinels are fixed in their post and observe the enemy with eyes in the default state;

- FGP/enemy contact: When they detect the enemy through squad or inorganic, situational awareness, the FGP uses PVS-7 night vision goggles and has longer detection range;

- MGP/default: MGP patrols along the GOP line with defined speed and detection range;

- MGP/enemy contact: When MGP have information about the enemy's location and movements, they adjust their speed;

- Reinforcement/default: Reinforce troops are stationed in the platoon;

- Reinforcement/enemy contact: When other assets detect the enemy and the platoon CCC receives this information, the reinforcement troops dispatch to predefined supplement posts;

- Reinforcement/waypoint: When the reinforcement troops reach their posts, they fixed in the post.

\subsubsection{Equipment}

Based on the tactical use of the TOD in our GOP border security system, TODs are located by considering height and distance from the GOP line. TODs work best when located close to the GOP line and when positioned relatively high. When there are multiple TODs, we locate them so that their total detection area is as large as possible. When a TOD detects an infiltration activity, it sends the information about the enemy to the battalion's CCC through a communication link.

\section{Analysis Under Optimized Infiltrator Behavior}

We describe an optimization model that is used to determine the infiltrator's behavior, i.e., the behavior of the infiltrator forces(the red force). The optimization model we form aims to determine what we view as the worst case behavior for the infiltrator in overcoming the highest border security level of the ROK Army(the blue force). In terms of military operations, knowing the strategies and tactics of the enemy significantly affects the friendly forces' course of action(COA). The propensity of the infiltrator needs to be described in order to use it as input when evaluating the GOP border security system.

GAs can be useful in military modeling for approximately solving different combinatorial optimization problem such as determining an adversary's $\mathrm{COA}^{[7]}$. For the Blue force, we assume the COA of the red force is unknown, and we take the worst-case perspective mentioned above by allowing the red force to optimize its behavior. Currently, the ROK Army bases its assumptions about the COA of the infiltrator on previous infiltrations from North Korea and predicted infiltrator scenarios, which are described in its field manual. ${ }^{[8]}$

\subsection{The infiltrator optimization problem}

Two scenarios are modeled based on the GOP border security system model. Given the ROK Army's maximum level of border security, the first scenario is developed based on the predicted infiltration scenario in the field manual ${ }^{[8]}$ without the triggered behavior of the infiltrators. We name this default scenario as scenario 1 . Scenario 2 is identical to scenario 1 up to the point at which the infiltrators contact the security guard. The objective of the infiltrator is to successfully pass through the DMZ and reach a pre-decided waypoint that is located south of the southern GOP line.

In modeling the infiltrator's behavior we use five decision variables to control that behavior, as enumerated below: 
- $x_{1}:$ Next waypoint $\in[5,70]$;

- $x_{2}:$ Avoid FGPs $\in[-100,0]$;

- $x_{3}$ : Avoid Reinforcements $\in[-100,0]$;

- $x_{4}:$ Avoid MGPs $\in[-100,0]$;

- $x_{5}:$ Speed of movement $\in[5,70]$;

An infiltrator has access to intermediate waypoints on his way from his origin to his destination waypoint. Decision variable $x_{1}$ is a weight that indicates how aggressively the infiltrator attempts to reach the next waypoint. Decision variable $x_{2}, x_{3}$, and $x_{4}$ concern how much weight the infiltrator places on avoiding blue forces in respective forms of FGPs, MGPs and reinforcements. A value of -100 represents maximum aversion to blue forces and 0 represents no aversion at all. Finally, $x_{5}$ controls the speed of movement of the infiltrator( $1 \mathrm{~km} / \mathrm{h}=14$ MANA unit). We consider two MOEs for the infiltrator: $m_{1}$ is the number of red casualties and $m_{2}$ is the (conditional) average time for the infiltrators to reach the final waypoint, conditioned on actually reaching that waypoint. Those two MOEs depend on $x_{1}, x_{2}, x_{3}, x_{4}$, and $x_{5}$ and we denote this dependence via $m_{1}\left(x_{1}, x_{2}, x_{3}, x_{4}, x_{5}\right)$ and $m_{2}\left(x_{1}, x_{2}\right.$, $\left.x_{3}, x_{4}, x_{5}\right)$. We assume that the infiltrator attempts to minimize a weighted sum of $m_{1}$ and $m_{2}$. Specifically, we formulate the infiltrator's optimization problem as (1):

$$
\begin{array}{rl}
\min _{x} & w m_{1}\left(x_{1}, x_{2}, x_{3}, x_{4}, x_{5}\right)+(1-w) m_{2}\left(x_{1}, x_{2}, x_{3}, x_{4}, x_{5}\right) \\
\mathrm{s.t} \quad & 5 \leq x_{1} \leq 70 \\
& -100 \leq x_{2} \leq 0 \\
& -100 \leq x_{3} \leq 0 \\
& -100 \leq x_{4} \leq 0 \\
& 5 \leq x_{5} \leq 70
\end{array}
$$

Where $w(0 \leq w \leq 1)$ is a weight that can put all weight an minimizing casualties $(w=1)$, all weight on minimizing time to reach the destination $(w=0)$, or anything on the continuum in between.

From our experiments, we find that when $w=1$, i.e., we minimize red casualties, that the red force evolves in a way to largely stay to the north of the
GOP line. So, most of the infiltrators stay above the GOP line at the time the simulation run terminates. For this reason, we incorporated $m_{2}$, the time to reach the final waypoint, into the objective function to induce the red forces to advance. That said, we use a small weight on the latter MOE, as we detail below:

- Scenario 2, MOE 1 $(w=1.0)$;

- Scenario 2, MOE 2( $w=0.95)$;

- Scenario 2, MOE 3(w=0.90);

The decision variables in the infiltrator's optimization model are nominally continuous. However, the objective function has no structure that lends itself to optimization by typical algorithms for (continuous) nonlinear optimization. So, we discretize the feasible region for $\left(x_{1}, x_{2}, x_{3}, x_{4}, x_{5}\right)$ and only allow them to take on integer values in this domain. Enumerating all such feasible solutions amounts to $4.225 \times 10^{11}$ points, which we term design points. Given that a simulation model must be run to estimate the objective function at a single design point, compete enumeration is not viable. So, we use a heuristic to approximately solve our model. In particular, we use a GA.

\subsection{GA in MANA}

For this study, we use the GA tool kit in MANA based on the GOP border security model which we described earlier. The genes in the GA correspond to the decision variables of the model specified in Section 3.1.

In one iteration of the GA, specific values for these genes are assigned, i.e., the chromosome is specified. Then, the infiltrators are placed in the corresponding scenario and the objective function is calculated for the border security system. Once the MOEs in the objective function have been estimated, the decision is made whether to keep or eliminate the chromosome in the subsequent generation. This process is repeated over generations with the goal of decreasing the specific weighted sum.

Fig. 4 demonstrates how chromosomes evolve from one generation to the next based on defined parameters, including population number, number of multi-runs, 


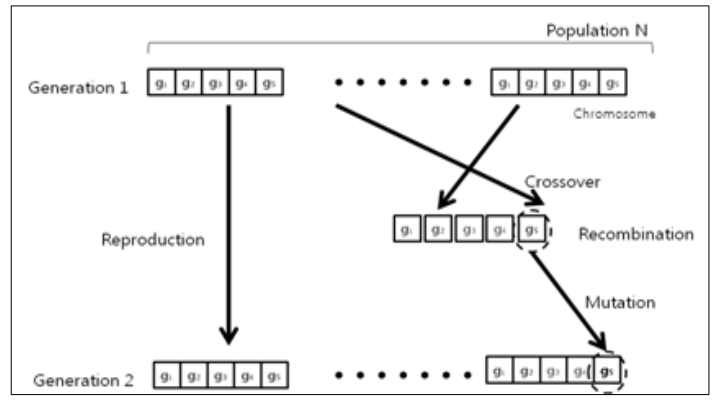

Fig. 4. Schematic diagram for the GA

mutation rate, and mutation strength ${ }^{[7]}$.

Before the GA scheme is executed, the size of its population, the mutation rate, the mutation strength, and number of multi-runs must be specified. The mutation rate represents the probability that genes will mutate in one generation. The mutation strength refers to the percentage of each gene's allocated range by which the gene's value will change if a mutation does occur. We have random mutations to infiltrators' genes. Genes in our schemes have an integer value so we have a choice to change the integer value due to mutation. Mutation can be useful in attaining an improved value of the MOEs compare to that of the original genes. Both mutation rate and strength should not be too high because they can destroy good chromosomes ${ }^{[7]}$. For this problem, we used a total $7.5 \times 10^{3}$ replications with a population size of 10 , with 5 multi-run, $5 \%$ mutation rate, $10 \%$ mutation strength and with $35 \mathrm{GA}$ generations.

\subsection{Simulation analysis}

The results of scenario 2 based on the GA are as shown in Fig. 5, Fig. 6, and Fig. 7. The best chromosomes(points which are denoted by blue circles) were obtained within 30 GA generation for each MOE.

Table 1 shows near optimal behavior of the infiltrator. As the weighting of MOE $m_{2}$ increases, we can predict the speed of movement increases but it is not always true, as table 1 demonstrates. The speed of movement from the MOE 2 to MOE 3 decreases since the behavior of the infiltrator involves five characteristics, and there are interactions when these variables interact.

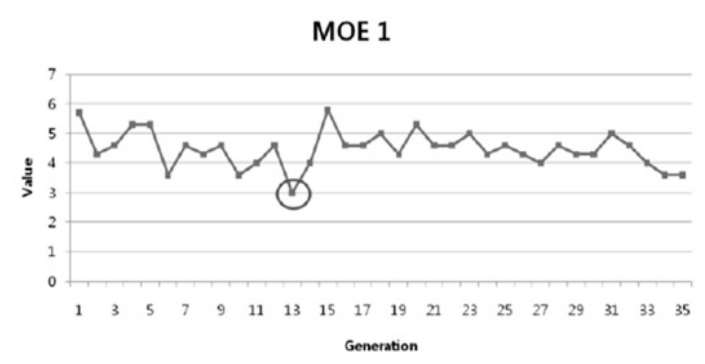

Fig. 5. MANA run results of scenario 2, MOE $1(w=1.0)$

MOE 2

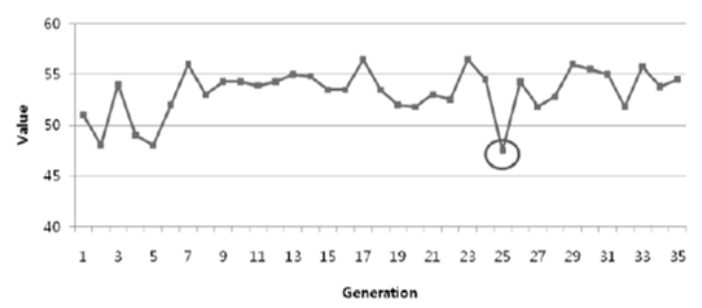

Fig. 6. MANA run results of scenario 2 , MOE $2(w=0.95)$

MOE 3

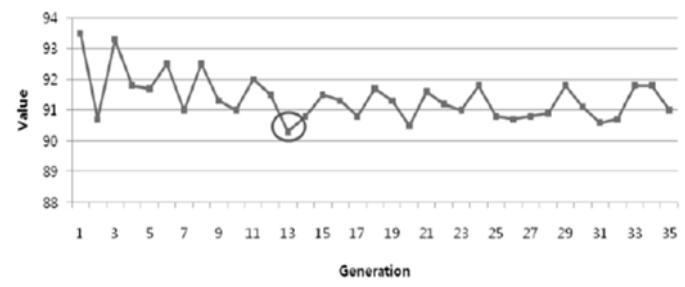

Fig. 7. MANA run results of scenario 2, MOE $3(w=0.9)$

Table 1. The results of GA for values of three weights in the objective function

\begin{tabular}{c|c|c|c|c}
\hline & $\begin{array}{c}\text { Scenario 1 } \\
\text { (Default) }\end{array}$ & $\begin{array}{c}\text { Scenario 2 } \\
(\text { MOD 1) }\end{array}$ & $\begin{array}{c}\text { Scenario 2 } \\
\text { (MOD 2) }\end{array}$ & $\begin{array}{c}\text { Scenario 3 } \\
(\text { MOD 3) }\end{array}$ \\
\hline Next Waypoint $\left(\mathrm{x}_{1}\right)$ & 30 & 5 & 28 & 45 \\
\hline FGP & 0 & -100 & -43 & -21 \\
\hline Reinforcement $\left(\mathrm{x}_{3}\right)$ & 0 & -90 & -34 & -11 \\
\hline MGP & 0 & -80 & -24 & -11 \\
\hline Moving Speed $(\mathrm{xs})$ & 56 & 20 & 56 & 44 \\
\hline
\end{tabular}

Also, from the results of $x_{2}, x_{3}$ and $x_{4}$, we can estimate how the infiltrator recognizes the relative 
Table 2. The results of 500 simulation runs with the best solution for scenario 2 and comparison between scenario 1 and 2

\begin{tabular}{c|c|c|c|c|c}
\hline & $\begin{array}{c}\text { Red } \\
\text { Casualties }\end{array}$ & Std. Dev & $\begin{array}{c}\text { Red } \\
\text { Casualty } \\
(\%)\end{array}$ & $\begin{array}{c}\text { Lower } \\
95 \%\end{array}$ & $\begin{array}{c}\text { Upper } \\
95 \%\end{array}$ \\
\hline $\begin{array}{c}\text { Scenario 1 } \\
\text { (Default) }\end{array}$ & 13.38 & 2.76 & 44.6 & 13.13 & 13.62 \\
\hline $\begin{array}{c}\text { Scenario 2 } \\
\text { (MOD 1) }\end{array}$ & 0.006 & 0.08 & 0.02 & 0 & 0.01 \\
\hline $\begin{array}{c}\text { Scenario 2 } \\
\text { (MOD 2) }\end{array}$ & 0.436 & 0.68 & 1.45 & 0.37 & 0.50 \\
\hline $\begin{array}{c}\text { Scenario 3 } \\
(\text { MOD 3) }\end{array}$ & 12.408 & 2.77 & 41.36 & 12.16 & 12.65 \\
\hline
\end{tabular}

threat from each border security resources. The infiltrator has the best characteristic when seeking to avoid the FGP the most, i.e., when the absolute value of $x_{2}$ exceeds that of $x_{3}$ and $x_{4}$.

Table 2 explicitly shows how the approximately optimized behavior affects the results of the infiltration in terms of red casualties. The second column, the MOE, represents the best value of each case as $w$ varies. The number of red casualties decreases dramatically when we move from scenario 1 to scenario 2 with $w=1$. In this case, as we mention above, the infiltrators largely stay north of the GOP line. A similar result appears to hold when we decrease $w$ to $w=0.95$, i.e., for scenario 2(MOE 2). However, these results are different in that in scenario 2(MOE 2) most of the infiltrators do reach their waypoint.

When we further decrease $w$ to $w=0.90$, the performance of the infiltrators has almost reverted to that of scenario 1. Based on these results, we can use scenario 2(MOE 2) for the nearly optimal behavior of the infiltrator for evaluating the border security system.

\section{Conclusion}

In this study, we formulated an optimization model and approximately solved it using a GA in order to capture near optimal behavior of an infiltrating force. In our experiments the GA obtains its best solution within 30 iterations.

When we compare the result of the human resource model of Sung $^{[2]}$ with the parameters revealed in his paper, we obtain comparable results to his work. Compare to his model, our model captures more detailed with respect to modeling the infiltrator, combined a human resource model and equipment model, which is separately implemented in his work, and takes less time to obtain the predicted detection rate and additional MOEs (measure of effectiveness). The results in Section 3.3 give two significant insights for our border security system.

First, optimizing the infiltrator's behavior can make a significant difference. Previous studies mostly do not consider the optimized behavior of the infiltrator in their scenarios and model the enemy similar to our scenario 1. But, the casualties of the infiltrators show the MOE between scenario 1 and scenario 2 can be significantly different.

Second, the quantitative results regarding the infiltrator's avoidance of each asset in our security system can be viewed as capturing their relative importance to our border security system. A previous study Sung ${ }^{[2]}$ suggests that the role of the MGP is minor compare to other assets because the range of the surveillance is short. But, the results of our simulation reveal the MGPs plays an important role to interdict the infiltrator since the MGP is capable of detecting and killing infiltrators who try to pass through gaps between the FGP and the reinforcements. Specifically in table 2, the values of $x_{4}$ are not minor compared to that of $x_{2}$ and $x_{3}$.

We found several weaknesses of the GA tool such as reliance of randomness when generating the initial population and redundant excursions to certain chromosomes. One reason for this behavior of the algorithm is that a memory structure is not used to avoid revisiting the same solution. For this reason, improvements to generate the initial solution intelligently or an adaptive search procedure that uses a memory structure could improve our results.

Our model can help battalion commanders to adjust 
the configuration and appropriate intensity of the security level while considering constraints including available assets and expected MOEs. Based on this study, the ROK Army can evaluate ongoing project, GOP unmanned border security system which substitute human resources to the cameras and sensors. Given the number of equipment, the ROK Army would reduce the human resources along with the GOP line instead of stationed security guards.

\section{References}

1. Galligan, D. P., Anderson, M. A., Lauren, M. K., \& McIntosh, C. G. (2007). MANA version 4 user manual. DTA.

2. Sung, C. (2005). Exploration of Matehmatical Modeling of the Border Security. Korea Advanced Institute of Technology (KAIST).
3. Reynolds, W. C. (1987). Flocks, Herds, and Schools: A Distributed Behavioral Model. Computer Graphics, 21(4): 25-34.

4. SEED Center for Data Farming. (n.d.). Retrieved 04 03, 2010, from http://harvest.nps.edu

5. Ilachinski, A. (2004). Artificial War: Multiagent-Based Simulation of Combat. World Scientific Publishing Co.

6. Lanchester, F. W. (1916). Aircraft in Warfare, the Dawn of the Fourth Arm. London.

7. McIntosh, C. G., \& Lauren, K. M. (2006). Genetic Algorithms Approach to Course-Of-Action Development Using the MANA Agent-Based Model. Journal of Battlefiled Technology, 19(3).

8. Security, FM 32-1 (Vols. FM 2-11). (2003). ROK Army Headquarter.

9. Sprague, B. K., \& Dobias, P. (2008). Modeling the Complexity of Combat in the Context of $\mathrm{C} 2$. The International C2 Journal, 2(2).

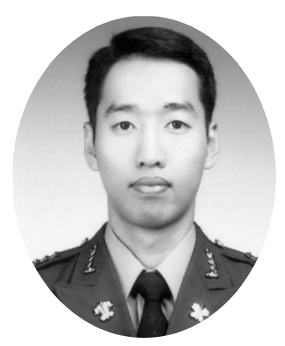

오 경 택 (kt6461@gmail.com)

2005 육군사관학교 이학사

2008 텍사스 오스틴대학 운영분석\&산업공학 석사

2012 현재 육군사관학교 수학과 강사

관심분야 : 모델링\&시뮬레이션, 국방 시뮬레이션, 메타휴리스틱

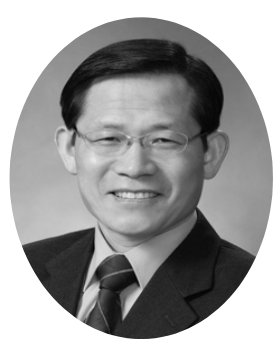

이 재 영 (leeis1001@yahoo.co.kr)

1980 육군사관학교 이학사

1988 미국 해군대학원 OR 석사

1995 미국 North Carolina State University OR\&통계학 박사

2000 현재 국방대학교 운영분석학과 교수

관심분야 : C4I 체계 효과분석, 국방 $\mathrm{M} \& \mathrm{~S}$ 개발 및 응용, 무기체계 비용 대 효과분석 